\title{
O CRESCIMENTO DA INDÚSTRIA DE RECICLAGEM DE EMBALAGENS DE ALUMÍNIO NO BRASIL E A FRAGILIDADE DOS INDICADORES SOCIAIS: UMA ABORDAGEM ESTATÍSTICA DESTE CENÁRIO
}

\author{
David de Oliveira Costa (UFF) dcosta.doc@gmail.com \\ Michelline Ouriques Gomes Costa michelline.ouriques@gmail.com \\ Carlos Francisco Simões Gomes (UFF) cfsg1@bol.com.br \\ Marcos dos Santos (IME) marcosdossantos_doutorado_uff@yahoo.com.br \\ Daniel Augusto de Moura Pereira (UFCG) danielmoura@ufcg.edu.br
}

\section{Resumo}

O objetivo desse trabalho é analisar o aspecto da sustentabilidade com uma perspectiva dos impactos socioambientais, relacionando-os aos índices de desempenho social, tomando por referência dados históricos de reciclagem das latas de alumínio no Brasil, classificação no Programa Internacional de Avaliação de Alunos (PISA) e do Índice de Desenvolvimento Humano (IDH), divulgado pela Organização da Nações Unidas (ONU). Fazendo um paralelo com os cenários do Japão (uma cultura reconhecida pela disciplina e educação) e, dos Estados Unidos da América (reconhecido como uma potência industrial, com seus processos robustos e excelentes performance produtiva. Outra métrica considerada neste estudo, foi o consumo de energia elétrica per capita, dos países supracitados, visto que esse indicador tem relação direta com o processo de reciclagem. Compreender a interação entre esses fatores é elementar para entender a dinâmica desse ambiente. Diante dos elementos analisados, pode-se constatar que o Brasil ainda não chegou à maturidade da consciência ambiental, e que o processo de inserção na cadeia produtiva de coleta seletiva está relacionado ao processo de obtenção de renda e de sobrevivência.

Palavras-chave: Analfabetismo; Impactos ambientais; Logística Reversa; Sustentabilidade.

\section{Introdução}

As embalagens se afirmam, em sua importância, ao longo da história e expressam aspectos e traços culturais e sociais. Pode-se constatar essas evidências em manuscritos bíblicos, do Antigo Testamento, onde se faziam necessários armazenar grãos, farinha, azeite etc. De 
acordo com o site especializado no mercado de latas, mundolatas.com, a necessidade em se obter o acondicionamento e a conservação dos alimentos era, de fato, extrema.

Os sites especializados em embalagem relatam que, nos anos de 1795 , o então sacerdote católico e cientista, Lazzaro Sallanzani, ao tentar invalidar a teoria da geração espontânea, pregada por John Needham, acabou por descobrir, por meio da experimentação, que ao colocar uma vedação mais eficientes nos recipientes de vidro e submeter à fervura e um determinado tempo, ele constatou que o surgimento de microrganismos ou bactérias tinha uma relação direta com o nível de oxigênio do recipiente. E, tempos após esse experimento foi retomado por Loius Paster, que ampliou esse estudo e, que atualmente é bastante aplicado nas indústrias de alimentos.

Mas, foi no período da primeira guerra mundial que esse artefato (embalagem) tomou um enfoque especial e, por questões estratégicas, era necessário desenvolver um método de transportar alimentos acondicionado de forma a preservar a estrutura dos alimentos para alimentar a tropa no front de batalha. Com isso, Bonaparte decide envolver a sociedade francesa e, oferece uma recompensa de 12.000 Francos pra quem conseguisse desenvolver algo que acondicionasse, conservasse de forma prolongada, os alimentos. Em 1802, Nicolas Appert aplica o princípio desenvolvido por Sallanzanni, ao adicionar à uma garrafa de vidro, hermeticamente fechada, legumes, carnes e peixe (frescos e cozidos) e, em seguida imergiu essa garrafa em água até ferver, durante algum tempo.

Isso foi o suficiente para que houvesse a garantia de alimentação das tropas. Atualmente, esse princípio ainda é muito aplicado e recebeu o nome de autoclave (tratamento térmico que consiste em manter determinado material sob temperatura elevada). E, em 1810, Peter Durand, aplicou o conceito estabelecido nas embalagens de forma mercadológica, ao desenvolver uma embalagem metálica (lata) para acondicionar biscoitos e bolachas e, em seguida esse conceito se expandiu para outros insumos.

Mas, ao longo da história percebe-se que aspectos culturais e sociais, ditam o estilo de consumo e geram demandas que a indústria entenderá tal cenário como uma demanda a ser atendida, de forma a gerar negócio e, dessa forma ótima oportunidade de fonte de riqueza. Outro fato impactante, neste contexto, são estilos políticos adotados que geram uma diferença considerável entre as classes sociais que, inevitavelmente desdobrará em impactos sociais significativos. As políticas públicas, quase sempre, não atendem ao seu propósito projetado e, nem sempre promovem às mudanças desejáveis. E, diante disso, essas classes menos 
assistidas, seguem atingidas por desigualdades sociais e escassez de recursos, de forma a garantirem a manutenção básica da sua família.

Para essas classes, restam trabalhos de baixo poder cognitivo e alto esforço físico, como este que é essencial na cadeia produtiva da reciclagem. Os catadores, são uma peça principal na manutenção e garantia desse fluxo. Diante disso, a necessidade de investimentos em ações que promovam, de forma sustentável, condições minimamente dignas, merecem ser entendidas como prioridades.

\section{Fundamentação Teórica}

\subsection{A lata de alumínio}

O mercado de latas de alumínio vem se consolidando ao longo do tempo, e no Brasil demonstra uma cadeia sólida e em crescente expansão. Quando teve início, nos anos de 1959, na cervejaria Norte Americana Coors, considerada uma grande inovação nesse segmento. Considerada uma embalagem ecologicamente limpa e o seu processo de geração do alumínio bruto, um processo agressivo. Tem uma ótima oportunidade de negócio e, uma forma de compensar o meio-ambiente é por meio do processo de reciclagem, visto que esse material tem $100 \%$ de aproveitamento. Um diferencial que esse segmento trabalhou foi a valorização da cadeia produtiva: consumo, coleta e reciclagem. Isso justifica o valor atribuído no processo de compra da sucata, em destaque no gráfico do preço médio da sucata, que segue, na Figura 5. Pode-se afirmar que tal segmento, criou um organismo para viabilizar o resultado expressivo que o segmento está desempenhando ao longo do tempo.

Segundo o IBRAM (2021), um ponto crítico, para o segmento de mineração, é que após a tragédia ocorrida na barragem em Brumadinho - MG, dispositivos legais tentam inviabilizar incentivos para o segmento de mineração, de forma a mexer bruscamente no sistema de tributação. E, com isso os critérios para as atividades de extração, se tornaram mais rígidas. A exemplo da proposta de lei PL 3913/2019, conforme destaque;

Proíbe o licenciamento ambiental de barragens de rejeitos e de barragens de resíduos industriais novas; estabelece regras de segurança e prazo para o descomissionamento das barragens de rejeitos e das barragens de resíduos industriais em construção ou existentes, ativas e inativas; e institui a Taxa de Fiscalização de Segurança de Barragens de Rejeitos (TFSBR). (BRASIL, 2021). 
Para que haja o princípio da sustentabilidade no segmento de fabricação de embalagens de alumínio, diante do expressivo crescimento sinalizado pelo mercado (gráfico 1), o processo de reciclagem deverá está alinhado à essa tendência e enorme desafio imposto.

Gráfico 1 - Volume de latas produzidas no Brasil

Produção(Bi)

35

30

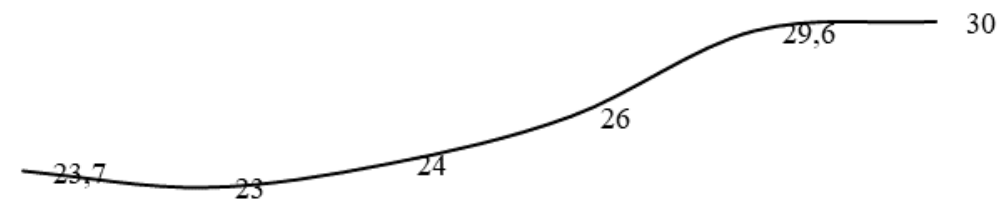

20

15

10

$\begin{array}{llllll}2015 & 2016 & 2017 & 2018 & 2019\end{array}$

Fonte: ABRALATAS (2020)

\subsection{Eficiência Energética}

Segundo ANEEL (2020), o objetivo do Programa de Eficiência Energética (PEE) é promover o uso racional e eficiente da energia elétrica em todos os segmentos da economia, estimulando o desenvolvimento de novas tecnologias e a criação de hábitos e práticas racionais de uso da energia elétrica. Bem como, viabilizar projetos relevantes à proposta e, que sejam viáveis economicamente. econômica de melhoria da eficiência energética de equipamentos, processos e usos finais de energia.

Para Magalhães e Domingues (2016), as inúmeras propostas de melhoria, com foco em de eficiência energética, podem ser fruto do processo de evolução tecnológico em curso. Bem como, uma resultante dos abusivos aumentos de tarifas de energia, que aceleram o processo criativo e à inovação. Diante disso, essa cadeia produtiva uniu numa proposta de diferenciação e altamente viável, as pautas da sustentabilidade ambiental e sustentabilidade financeira, ao promover ações com ênfase na reciclagem de embalagens pós-consumo.

Esteves et al. (2014), estimam que o tempo de circulação de uma lata, desde a sua fabricação até o processo de reciclagem, é de aproximadamente 60 dias. Um ganho expressivo nesse processo é com o uso da energia elétrica, onde para reciclar o alumínio são gastos apenas 5\% 
da energia utilizada na extração e que, para cada $1.000 \mathrm{~kg}$ de alumínio reciclado equivale a 5 mil $\mathrm{kg}$ de minério bruto (bauxita). Logo, um processo viável financeiramente e ambientalmente adequado.

Percebe-se que o fator de consumo de energia elétrica versus à taxa de crescimento do país (gráfico 2), é um indicador fundamental para entender possíveis aspectos da vida social e, grandes oportunidades de melhoria no segmento industrial. Percebe-se que o Brasil tem performance referencial, quando comparado a Japão e USA. Destaca-se também, a estabilidade nos índices nessa linha do tempo.

Gráfico 2 - Fator de consumo Energia Elétrica $x$ PIB

\section{Fator (kg petróleo/per capita)/USD}

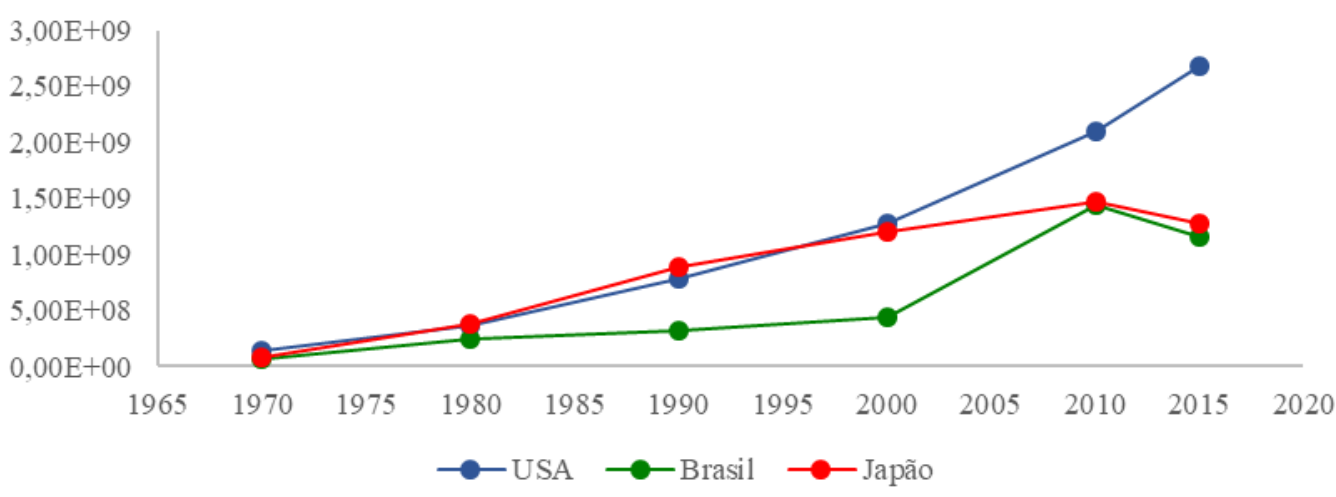

Fonte: Banco Mundial (2021)

Para que haja crescimento e riqueza num país, o desenvolvimento das atividades econômicas deverão se utilizar da infraestrutura. Logo, subentende-se que os índices de consumo de energia deverão acompanhar esse crescimento. A composição desse índice, considera a energia elétrica convertida em base de consumo de petróleo por pessoa (Tabela 1). De forma a entender a relação de consumo com o crecimento populacional do país. Existe uma necessidade latente de ampliar, de forma agressiva, a matriz energética global, atual.

Para Tolmasquim et al. (2007) entendem que, um dos entraves são a legislação vigente, e afirmam que é necessário analisar esse processo sendo: geração, transmissão e distribuição. E, para cada etapa existe uma lei específica. Logo, a complexidade jurídica aplicada à essa pauta, dificultam os avanços de propostas de alteração na matriz energética em vigor. 


\begin{tabular}{cccc}
\hline kg petróleo/per capita & USA & Brasil & Japão \\
\hline 1970 & $7.569,08$ & 715,84 & $2.458,36$ \\
1980 & $7.942,25$ & 943,30 & $2.950,14$ \\
1990 & $7.671,77$ & $1.473,39$ & $3.551,16$ \\
2000 & $8.056,86$ & $1.516,60$ & $4.083,83$ \\
2010 & $7.161,55$ & $1.531,76$ & $3.893,27$ \\
2015 & $6.806,20$ & $1.561,87$ & $3.428,56$ \\
\hline
\end{tabular}

Fonte: Banco Mundial (2021)

\subsection{Coleta Seletiva}

De acordo com a Associação Brasileira do Alumínio (ABAL, 2002), o processo de reciclagem no Brasil tem grande relevância devido ao aumento do consumo de bebidas e alimentos envazados em latas de alumínio. Assim, o processo de reciclagem gera impactos positivos no sistema financeiro, ambiental e social, gerando novas oportunidades de melhorias no processo de reciclagem. Isso se justifica pelo aumento crescente, ano a ano, do número de latas de alumínio recicladas.

Nesse sentido, essa atividade gera oportunidades de trabalho e renda (aproximadamente $\mathrm{R} \$$ 850 milhões/ano). Assim, o processo de reciclagem gera impactos positivos na economia, redução de matriz energética, criação de novos postos de trabalho, desenvolvimento de novos mercados, conscientização ambiental e inclusão social. Como respaldo jurídico, a lei 12.305/2010, Política Nacional de Resíduos Sólidos (PNRS), que abarca às práticas da coleta seletiva e, destaca a responsabilidade compartilhada ao longo da vida do produto.

XVII - responsabilidade compartilhada pelo ciclo de vida dos produtos: conjunto de atribuições individualizadas e encadeadas dos fabricantes, importadores, distribuidores e comerciantes, dos consumidores e dos titulares dos serviços públicos de limpeza urbana e de manejo dos resíduos sólidos, para minimizar o volume de resíduos sólidos e rejeitos gerados, bem como para reduzir os impactos causados à saúde humana e à qualidade ambiental decorrentes do ciclo de vida dos produtos, nos termos desta Lei; (BRASIL, 2010).

Afirma também que, o Brasil desde 2001, se firma numa posição de destaque, a nível global, na reciclagem de latas de alumínio, com crescentes índices acima de $85 \%$ e, que nos últimos anos chegou à marca dos 96\%, sendo um benchmark para os demais países. Isso representa um volume de 121,1 mil toneladas sobre o total de latas consumidas, sendo assim compreendido como um processo estável e sólido. Fruto de um processo árduo e com muitos aprendizados, já que, desde a década de 1990, que essa cadeia produtiva (reciclagem), mostra um crescimento acentuado, inclusive com desenvolvimento de tecnologias de ponta e rearranjo dos seus processos. 
Nesse contexto, a reciclagem do alumínio se torna uma atividade de alta rentabilidade, sendo um investimento totalmente viável, ao longo da cadeia produtiva. E, que a relação equalizada da sustentabilidade, terá relação direta com os índices de consumo versus percentual de coleta e reciclagem deste insumo.

Um aspecto relevante nessa cadeia logística e da reciclagem, passa por questões sociais significativas, onde aspectos do equilíbrio nessa cadeia não garante a devida sustentabilidade do sistema. A margem de lucro dos atravessadores (sucateiros) entre catadores e a indústria final, torna-se desbalanceada e com isso torna-se um fator negativo desse fluxo.

Como pode-se observar o preço médio Tabelado (gráfico 3) para os insumos (destaque para os insumos de embalagens), determinará quais serão as prioridades no processo de seleção dos profissionais catadores, onde a relação densidade (volume ocupado na carroça) e preço pago pelo insumo.

Gráfico 3 - Preço médio (R \$/kg) de negociação de sucatas

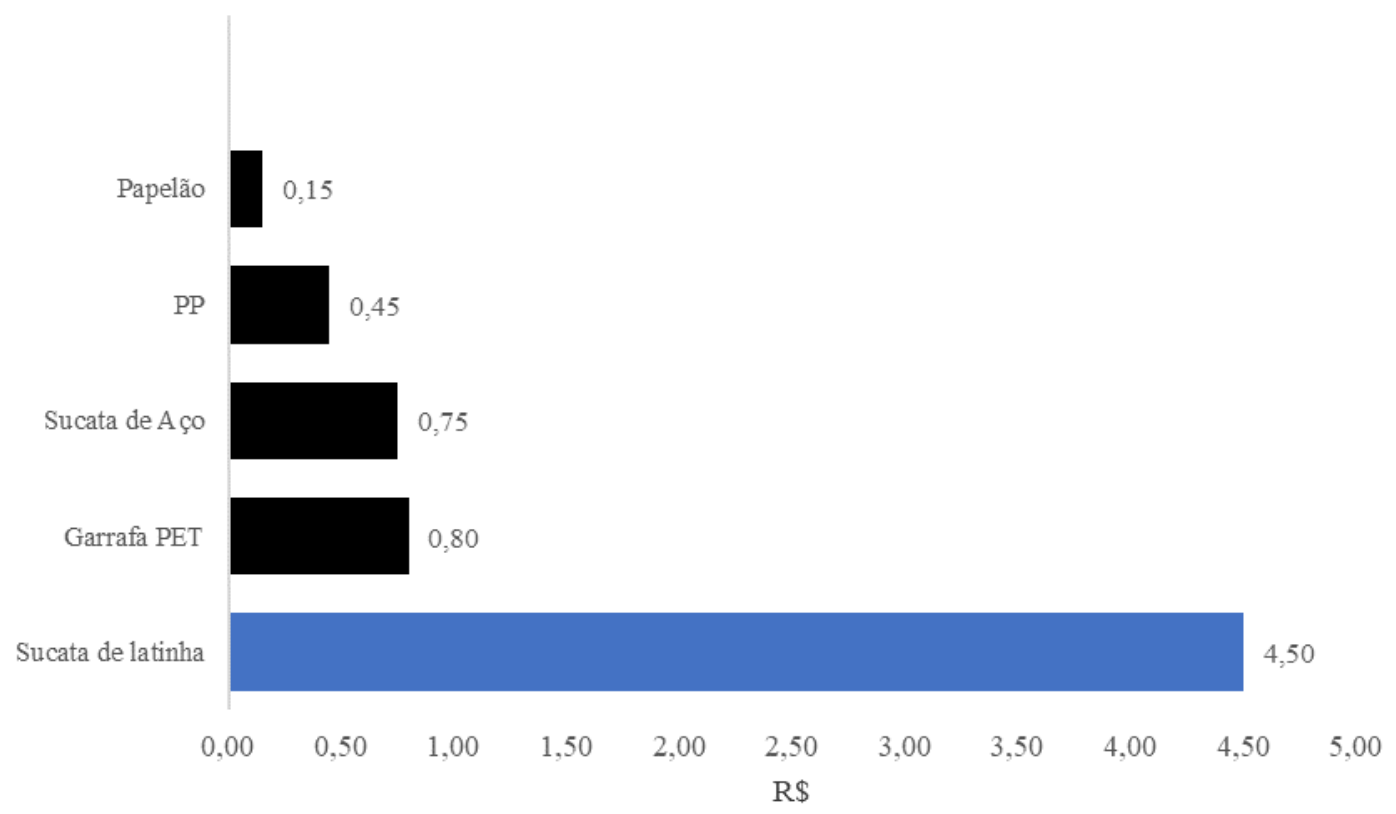

Fonte: ANCAT (2021)

\subsection{Logística Reversa}

Para Demajorovic e Migliano, desde os anos 1980 que o conceito da logística reversa ou logística verde é difundido. Porém, efetivamente observa-se a sua aplicação nos diversos segmentos do mercado. E, torna-se apenas um diferencial atrativo e não uma prática de negócio sustentável, baseado no tripé (ambiental, social e econômico). O Plano Nacional de Resíduos Sólidos (PNRS) visa minimizar os impactos gerados por esses insumos (resíduos 
pós-consumo), segundo a ABRALATAS, os resíduos de embalagens podem corresponder a $20 \%$ dos resíduos totalizados, no Brasil.

Importante destacar a relevância de uma legislação específica (Lei 12.305/2010) com essa ênfase, pois de forma direta, atribui-se responsabilidade compartilhada entre empresa fabricante, importadores, distribuidores e consumidores deste produto ou insumo tem a responsabilidade pelo ciclo de vida total desse item.

XVII - responsabilidade compartilhada pelo ciclo de vida do produto: conjunto de atribuições individualizadas e encadeadas dos fabricantes, importadores, distribuidores e comerciantes, dos consumidores e dos titulares dos serviços públicos de limpeza urbana e de manejo de resíduos sólidos, para minimizar o volume de resíduos sólidos e rejeitos gerados, bem como para reduzir os impactos causados à saúde humana e à qualidade ambiental decorrentes do ciclo de vida dos produtos, nos termos desta Lei. (BRASIL, 2010).

Para Paschoal (2007), é necessário considerar a emissão de CO2 gerada pelos veículos à queima de combustível (automotor), que realizam o sistema logístico em toda malha e extensão brasileira. Pois, ao percorrer a distância, durante a atividade, intrinsecamente um teor de poluição foi acrescentado à atmosfera. Para efetivar essa base de consumo e de poluição é necessário considerar: tipo de combustível aplicado, distância percorrida, performance de consumo do veículo, condições de manutenção do veículo etc. Logo, a logística reversa deverá ser mais um recurso estrutural nessa cadeia e, não apenas como chave central da resolução dessa problemática. Entendendo que parte desse percurso é realizado por transporte de tração animal e até mesmo de tração mecânica humana.

\subsection{Indicadores Sociais e o Perfil do Profissional da Reciclagem}

A categoria dos profissionais da reciclagem, conhecida popularmente como catadores, tem a sua definição oficializada Classificação Brasileira de Ocupações (CBO), sob o registro 519205, desde 2002. Nessa classificação, segundo o Ministério do Trabalho e Emprego (2021), o escopo aborda algumas atividades, como: catar, selecionar, vender etc. E, destacam os materiais recicláveis como: alumínio, aço, papel, papelão, plástico e vidro.

Stegani et al. (2018), entendem que as condições e cenários socioeconômicas do país (isso tende a se agravar, dependendo da região a ser considerada) levam essa atividade ser uma alternativa de sua sobrevivência e existência. Outro ponto relevante, nesse entendimento é que no perfil desses profissionais, apresentam aspectos que são desfavoráveis a eles: o baixo nível de escolaridade e idade avançada. Isso, por si só, já é um impeditivo para que essas pessoas almejem uma atividade distinta da atual no mercado de trabalho formal. Os dados que seguem 
(gráfico 4 e gráfico 5), são da Região Sul, do Norte do Paraná, mas reflete a realidade dos grandes centros urbanos do país.

Gráfico 4 - Faixa etária dos profissionais da reciclagem

Análise do perfil dos profissionais da reciclagem

Faixa etária
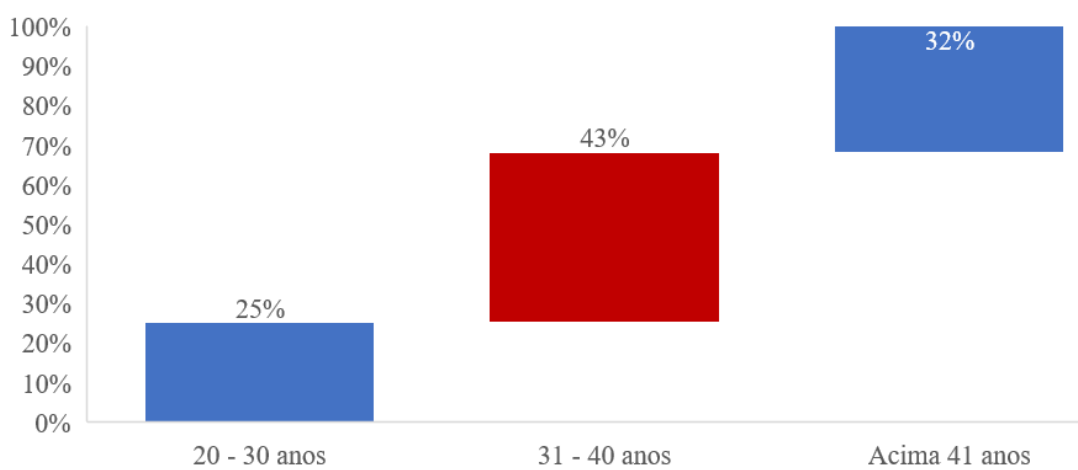

- 30 anos

$31-40$ anos

Acima 41 anos

Fonte: Stegani et al. (2018)

Gráfico 5- Nível de escolaridade dos profissionais da reciclagem

Escolaridade dos profissionais da reciclagem

Escolaridade

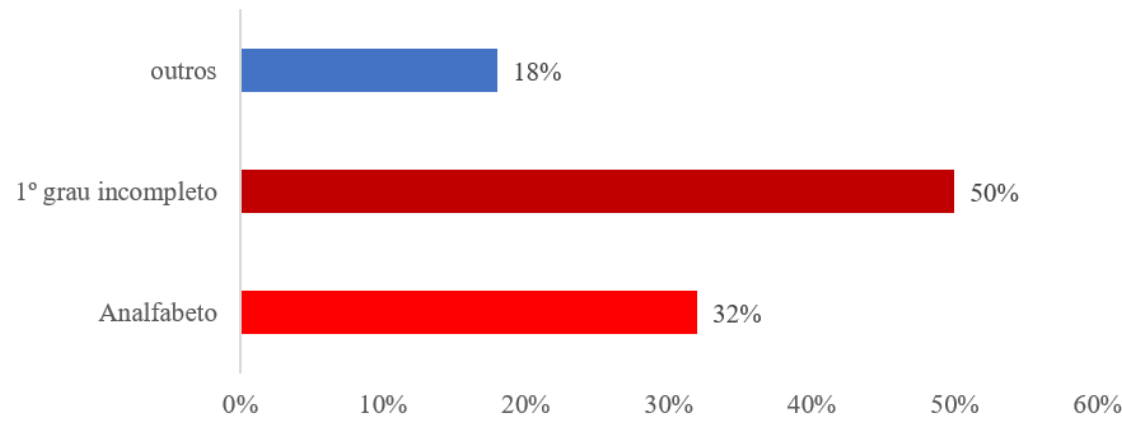

Fonte: Stegani et al. (2018)

\subsection{Sustentabilidade Aplicada}

Zulpo et al. (2020), entendem que o conceito estruturado para a sustentabilidade está fundamentado nas seguintes dimensões: econômica, ambiental e social. E, que diante disso, a formulação de indicadores de desempenho seja estabelecida como aspecto elementar do gerenciamento. Sislian (2020), avalia que as métricas voltadas à perspectiva econômica, são fundamentalmente expressas pelos índices de energia (eletricidade, água, gás etc.). Ao longo da cadeia produtiva, não sendo diferente da indústria da reciclagem, como aborda este estudo, é necessário que todas as dimensões sejam contempladas e que consiga atender às respectivas demandas.

A sustentabilidade empresarial é um processo evolutivo, criativo e sistêmico, cada vez mais valorizado por investidores e consumidores, não se tratando de um 
modismo. Portanto, espera-se que as empresas possam gerar lucro e, simultaneamente, contribuir para a realização de objetivos sociais e ambientais, mediante a integração da responsabilidade social enquanto investimento estratégico no núcleo da sua estratégia empresarial. (SANTOS, 2020)

Mediante a esse entendimento, pode-se seguir esse raciocínio para as perspectivas social e ambiental. É indiscutível o entendimento de que, o balanceamento entre as distintas perspectivas da sustentabilidade (Figura 1) proporcione desenvolvimento amplo e, consequentemente melhoria da qualidade de vida dos agentes envolvidos.

Figura 1 - Estruturação da sustentabilidade e seus pilares
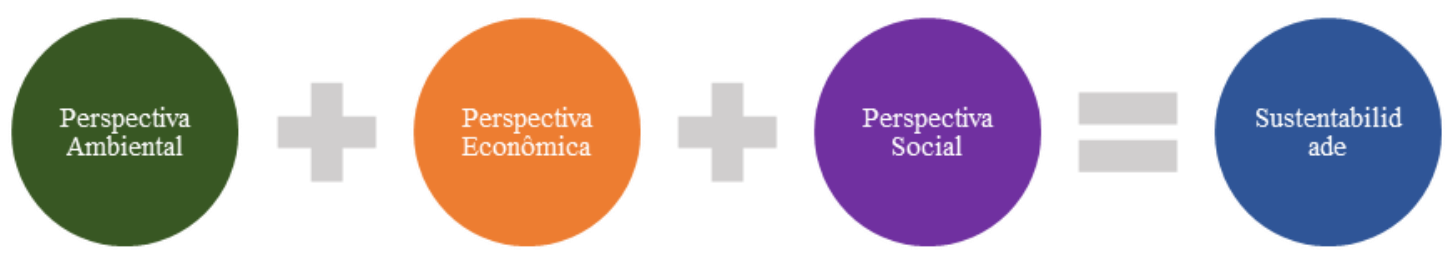

Fonte: Autores (2021)

\section{Metodologia}

Este trabalho trata de uma pesquisa bibliométrica, baseada em dados oficiais da Associação das Fabricantes de Latas do Brasil (ABRALATAS), sobre a performance da indústria de reciclagem no país (comparado ao Japão e EUA), dados oficiais do Índice de Desenvolvimento Humano (IDH) divulgado pela Organização da Nações Unidas (ONU) e o resultado das notas no Programa Internacional de Avaliação de Alunos (PISA), divulgados pela Organização para a Cooperação e o Desenvolvimento Econômico (OCDE), que mede a nível educacional refletido nos respectivos países. E, por meio da análise da correlação (coeficiente de Pearson) entender a dinâmica e interação entre as variáveis.

No esquema que segue (Figura 2), é possível verificar um fluxo metodológico aplicado a este estudo. Diante da performance de reciclagem e do processo de viabilidade da cadeia produtiva nos diferentes materiais (PET, vidro e latas de alumínio) que se mostram robustos, é possível analisar os índices de performance de coleta e reciclagem, cruzando com indicadores sociais de Educação e de Desenvolvimento Humano e entender que esses fatores tendem a se correlacionar. Sendo assim, para estruturar a base de dados para efetivamente analisar, considerou-se as médias dos três últimos resultados, pontuado em cada indicador supracitado.

Figura 2 - Fluxo metodológico do artigo 


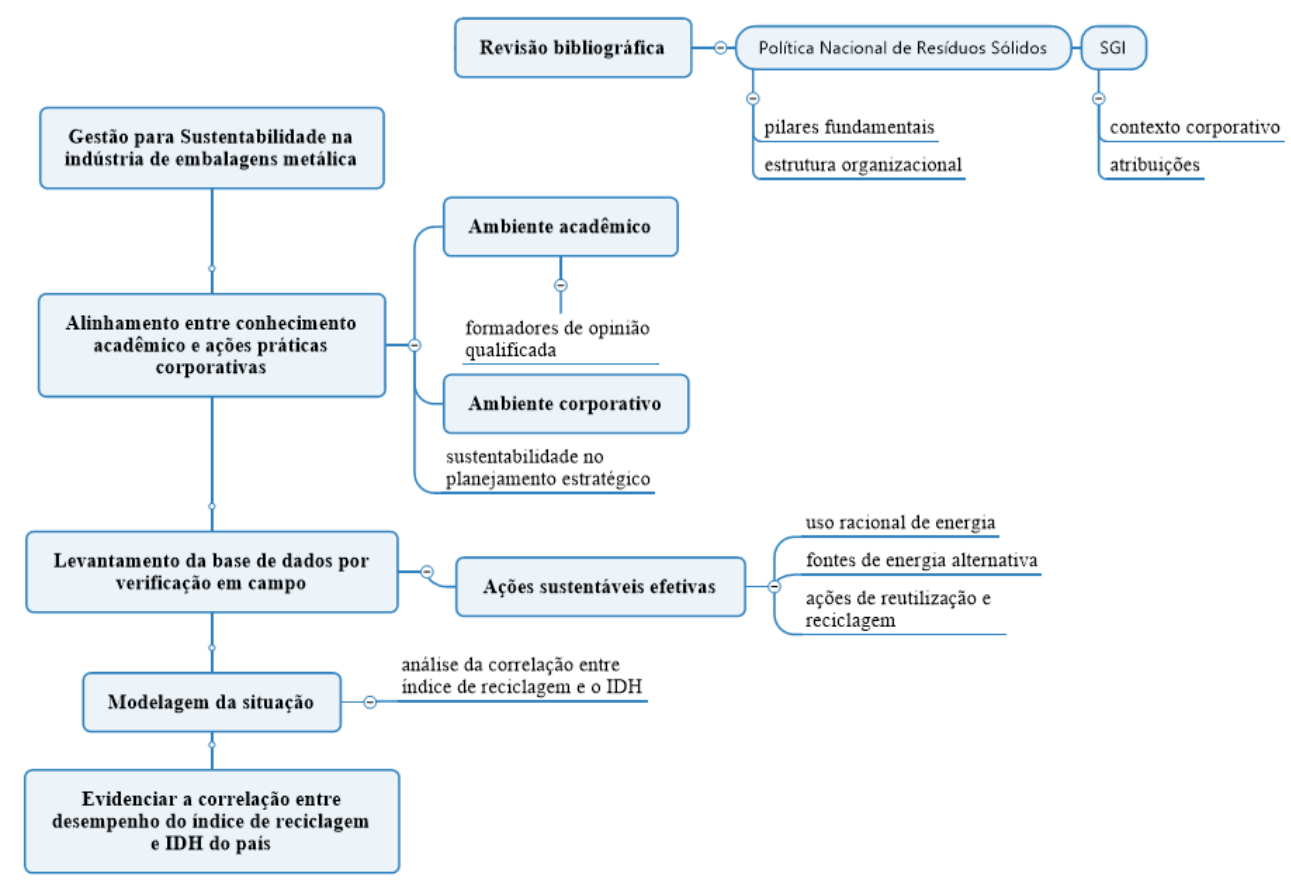

Fonte: Autores (2021)

\section{Resultados}

Conforme dados históricos do volume de reciclagem das latas de alumínio no Brasil, dos últimos resultados que o país obteve no Programa Internacional de Avaliação de Alunos (PISA) e no Índice de Desenvolvimento Humano (IDH) divulgado pela Organização da Nações Unidas (ONU), é possível inferir que o desempenho obtido nos índices de reciclagem não está atrelado ao nível de educação ou de consciência ambiental, mas sim a uma forma de obtenção de renda e de sobrevivência primária.

Diante do desempenho nos índices de reciclagem e do processo de viabilidade da cadeia produtiva nos diferentes materiais (PET, vidro e latas de alumínio) que se mostram robustos, é possível analisar os índices de performance de coleta e reciclagem, cruzando com indicadores sociais de Educação e de Desenvolvimento Humano e entender que esses fatores tendem a se correlacionar diretamente.

Afim de garantir a estrutura dos dados e, consequentemente o poder da análise, foi aplicado o teste para estimar o tamanho da amostra em questão. Como observado, para se obter uma amostra com 5\% de erro atribuído e nível de confiança de 95\%, basta considerar o tamanho da amostra 3, conforme tabulação (Figura 3).

Figura 3 - Tabulação para definir tamanho da amostra para análise 


\section{Tamanho Amostral para Estimação}

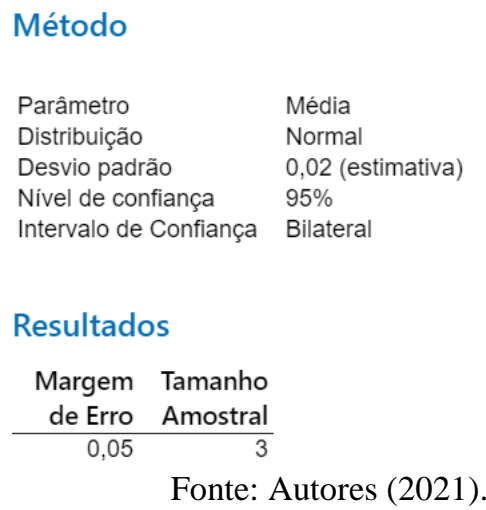

Mediante tal informação, considerou-se a média das últimas notas, dos índices supracitados. Conforme observa-se a correlação entre o IDH e o \% de reciclagem (gráfico 6), o coeficiente de Pearson ( $\rho$ ) obtido foi de $-0,937$ ou seja, quanto maior o volume reciclado, menor o Índice de Desenvolvimento Humano atrelado. Quando analisada a correlação entre \% de reciclagem e a nota do PISA, observa-se que o coeficiente de Pearson foi de $-0,829$, segue-se o mesmo raciocínio, quanto menor a nota do PISA, maior o volume reciclado. Quando se analisou a correlação entre PISA e IDH, o coeficiente obtido foi de 0,972 , de forma a entender que existe uma relação direta, ou seja, quanto maior o IDH, maior será a nota do PISA. Ainda é possível verificar a análise de regressão dessa matriz, que se define pela seguinte expressão: $\%$ Reciclagem $=3,456-23,70 * I D H+0,03788 *$ PISA. 


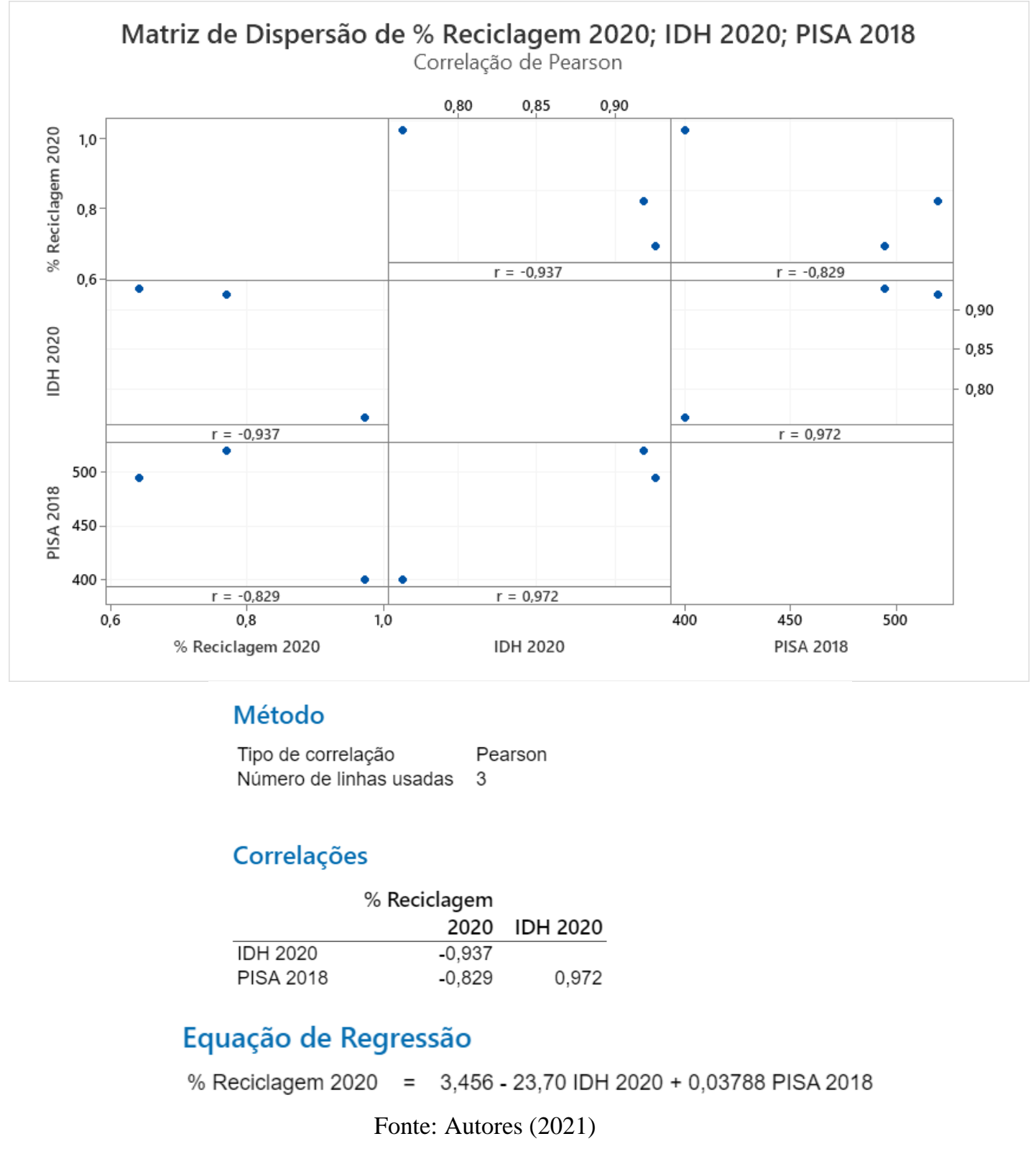

Garson (2009), entende que o coeficiente de correlação de Pearson ( $\rho$ ) é uma medida de associação linear entre variáveis e, é aplicada para estabelecer se as forças entre as variáveis são significativas. Diante disso, aplica-se o critério (Tabela 2).

Tabela 2 - Nível de significância das correlações e auto correlações

\begin{tabular}{|c|c|}
\hline Correlação & Nível de significância \\
\hline$\rho<-0,65$ & Significativa e negativa \\
\hline$-0,65<\rho<0,65$ & Pouco significativa \\
\hline$\rho>0,65$ & Significativa e positiva \\
\hline
\end{tabular}

Fonte: Autores (2021)

Como observa-se (Gráfico 7), o eixo Y do gráfico, indica o percentual de embalagens pós consumo recicladas e, no eixo $\mathrm{X}$ aponta as variáveis de desempenho social (IDH e PISA). 
Logo, é possível entender que existe uma forte inclinação da reta de correlação, sinalizando que o percentual reciclado é inversamente proporcional aos índices de desempenho sociais. Ou seja, uma região que tenha um alto índice social e cognitivo, atividades secundárias, como a de catador de recicláveis, não são praticadas. E, dessa forma específica a cadeia produtiva é afetada.

Gráfico 7 - Análise gráfica entre os fatores analisados

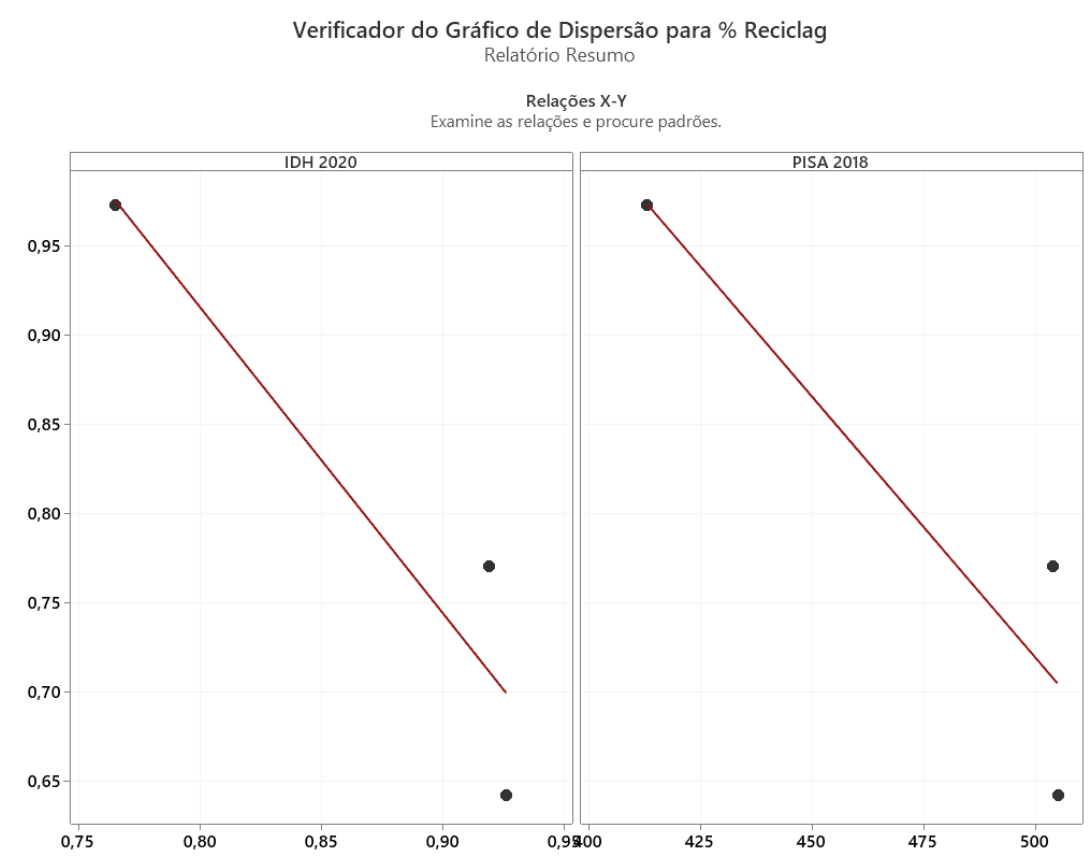

Fonte: Autores (2021)

Como percebe-se, o Brasil apresenta um índice expressivo, na reciclagem e, aponta com índice de desenvolvimento humano, comparado a EUA e Japão, preocupante (Gráfico 8). 


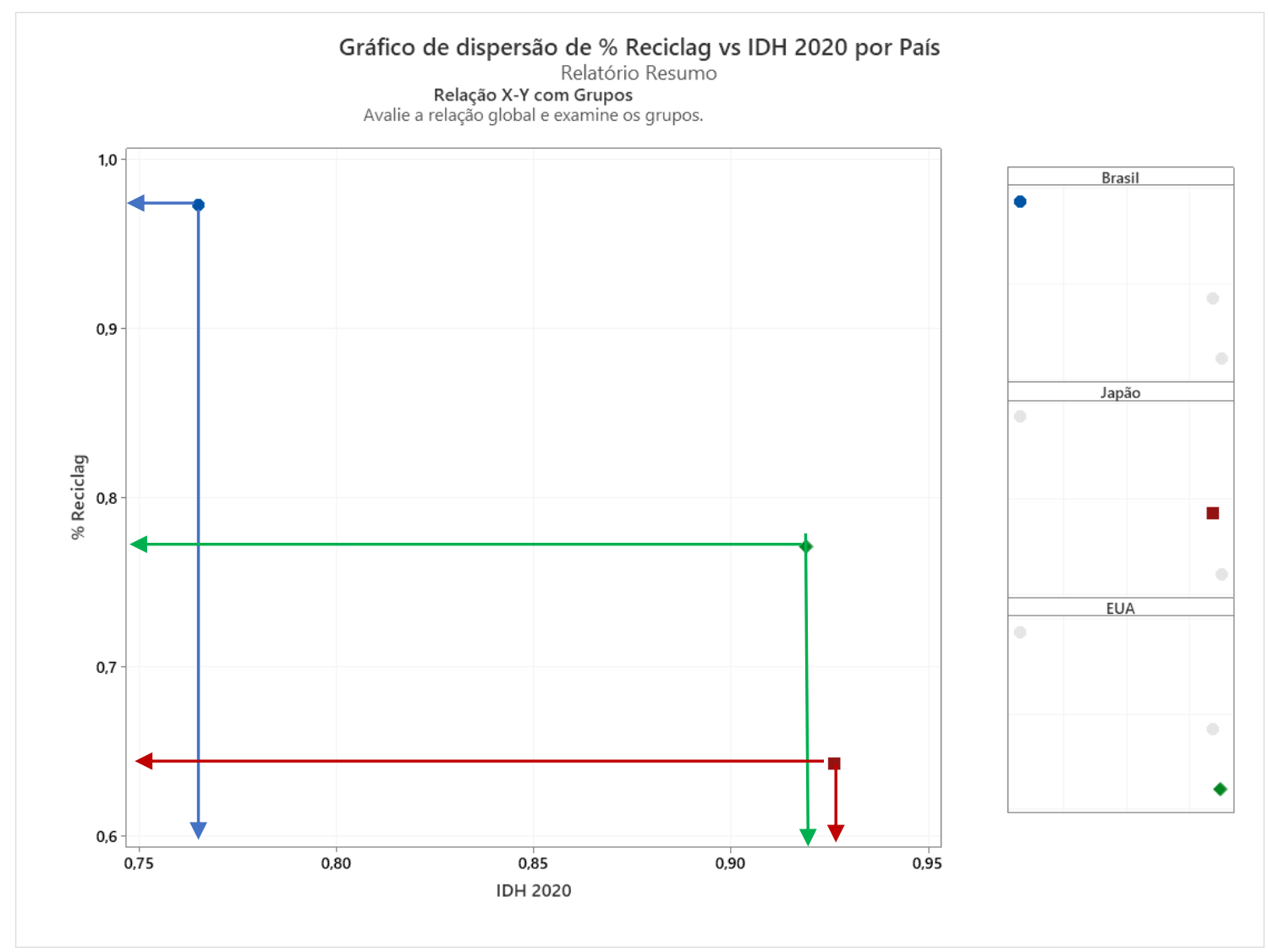

Fonte: Autores (2021)

A imagem é similar, quando analisamos isoladamente, o desempenho da avaliação PISA. Esses índices apresentam traços e aspectos semelhantes. E, estão relacionados diretamente com a educação da qualidade e com políticas públicas. Dessa forma, fica fácil entender o modelo de gestão educacional e político, bem como os resultados alcançados ao longo do tempo, entre os países supracitados (Gráfico 9). 


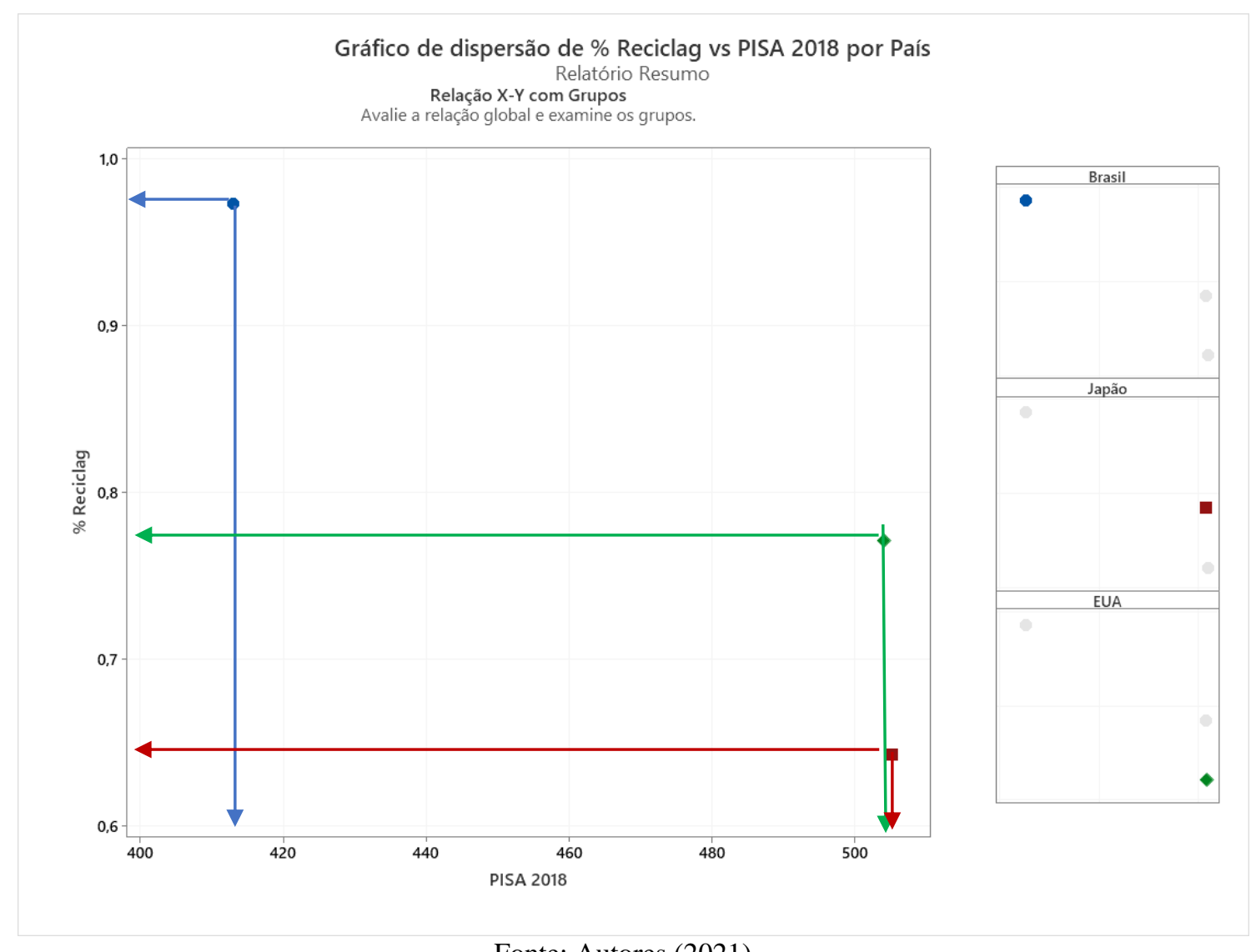

Fonte: Autores (2021)

\section{Discussões}

Diante do resultado, fica evidente que as ações e políticas públicas criadas, devem contemplar aspectos que atendam aos cidadãos das diversas camadas sociais. Pode-se constatar, nesse estudo, que de fato não chegamos à maturidade da consciência ambiental, mas que o processo de inserção na cadeia produtiva de coleta seletiva, é um processo de obtenção de renda e de sobrevivência.

Assim, quando comparado às realidades dos Estados Unidos da América, uma potência industrial e com ótimo desempenho social, em conjunto com o desempenho do Japão, um país em que a cultura milenar educacional e pela sua forma racional de enxergar o mundo, o Brasil se destaca nesse requisito, mas não implica que é consequência da consciência ambiental. Como exposto (Gráfico 10), sendo considerada como uma métrica secundária, caso os índices de reciclagem sinalizassem uma crescente, certamente o comportamento nos índices de consumo de energia elétrica ( $\mathrm{kg}$ de petróleo/per capita), tenderiam a minimizar, tendo um ganho ambiental considerável, diante à demanda crescente.

Gráfico 10 - Análise consumo de energia elétrica entre os países analisados 


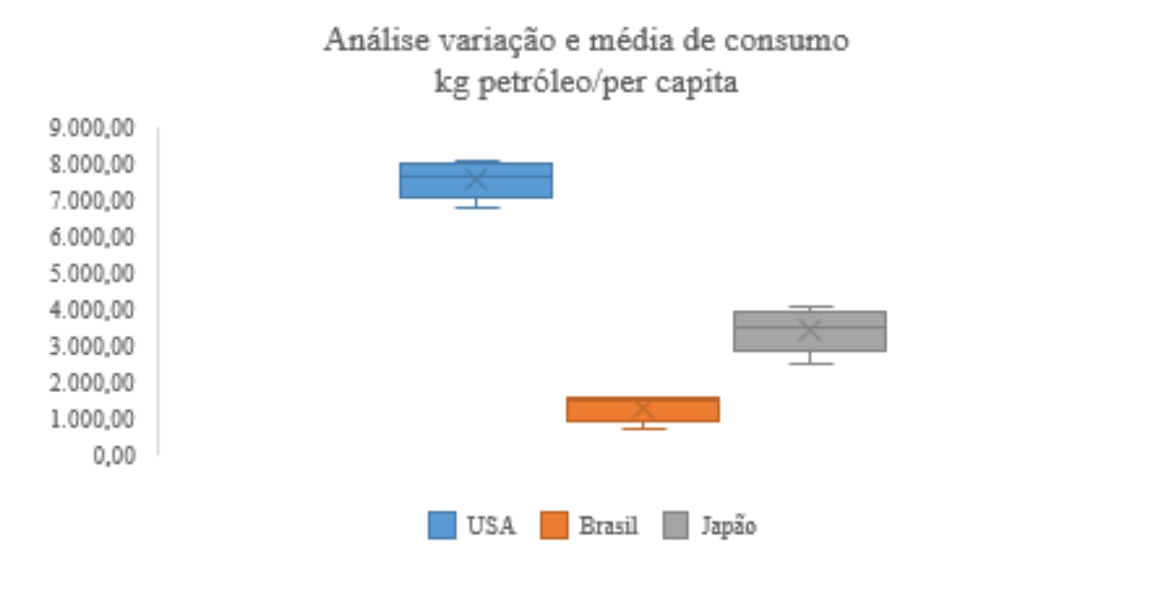

Fonte: Banco Mundial (2021)

Certamente, que a cadeia produtiva (indústrias do alumínio), nesses países já identificaram esse potencial, mas para que se alcance esse desempenho que o Brasil apresenta, é necessário um alto volume de coleta (o que não retrata a realidade dos países comparados). Ou seja, é necessário que o número de profissionais de coleta de sucata (catadores) seja expressivo.

\section{Considerações Finais}

Supostamente, um grande desafio deste século, está em práticas alternativas de um eficaz gerenciamento dos resíduos, sem que lixões e aterros sanitários se espalhem pelos grandes centros e, com isso gere-se maiores complicações ao sistema orgânico. Fica evidente que no ambiente corporativo, bem como na esfera política, tem espaço para implementar ações com base científica que atendam substancialmente uma camada sensível da sociedade. Um ponto sensível nessa cadeia produtiva é o catador de resíduos, que sendo uma parte fundamental nesse processo, é o elemento mais afetado.

Pois, muitas vezes, recorre a intermediários/atravessadores (donos de sucatas) que regulam, para baixo, a Tabela de preços praticadas em determinadas regiões, sendo considerado como grandes carteis deste segmento produtivo, sem que haja uma distribuição igualitária dos lucros. Entende-se que já existem dispositivos legais, Lei 12.305, para regular a importância dessa atividade e, classificá-la como elemento vital de camadas sociais menos favorecidas.

VIII - o reconhecimento do resíduo sólido reutilizável e reciclável como um bem econômico e de valor social, gerador de trabalho e renda e promotor de cidadania; (BRASIL, 2010).

\section{Referências}


ABRAlatAS. (2020) Relatório Técnico de Análise da Viabilidade Técnica e Econômica da Logística Reversa de Latas de Alumínio para Bebidas.

AGÊNCIA NACIONAL DE ENERGIA ELÉTRICA. Programa de Eficiência Energética. [acesso em 25 jul. 2021]. Disponível em: www.aneel.gov.br.

ASSOCIAÇÃO BRASILEIRA DOS FABRICANTES DE LATAS NO BRASIL. [acesso em 21 mai. 2021]. Disponível em: www.abralatas.org.br

ASSOCIAÇÃO BRASILEIRA DAS INDÚSTRIAS DE VIDRO. [acesso em 23 mai. 2021]. Disponível em: https://abividro.org.br/

ASSOCIAÇÃO BRASILEIRA DA INDÚSTRIA DO PET. [acesso em 23 mai. 2021]. Disponível em: http://www.abipet.org.br/

ASSOCIAÇÃO NACIONAL DE CATADORES E CATADORAS DE MATERIAIS RECICLÁVEIS. [acesSo em 23 mai. 2021]. Disponível em: https://www.ancat.org.br/

CEBRACE. [acesso em 23 mai. 2021]. Disponível em: https://www.cebrace.com.br/\#!/enciclopedia/interna/ahistoria-do-vidro

CONTE, P., Souza, E. L., Nogueira, M. R. C.; Soares, F. A. S. M. (2018). Avaliação Físico-química e Sensorial de Espumante Moscatel Envasado em Lata de Alumínio; Evidência, Joaçaba v. 18, n. 2, p. 161175, jul./dez.; https://doi.org/10.18593/eba.v18i2.19078.

ESTEVES, L., Marsalha, E. G., CASTRO, M. M. R., LINS, V. F. C. (2014). Resistência à corrosão de latas de alumínio em contato com cerveja; Tecnol. Metal. Mater. Miner., São Paulo, v. 11, n. 3, p. 229-235, jul./set.

GARSON, G. D. (2009). Statnotes: Topics in Multivariate Analysis. Disponível em: http://faculty.chass.ncsu.edu/garson/PA765/statnote.htm

INSTITUTO BRASILEIRO DE MINERAÇÃO. [acesso em 25 jul. 2021]. Disponível em: www.ibram.org.br. Magalhães, A. S., Domingues, E. P. (2016). Aumento da Eficiência Energética no Brasil: Uma Opção para uma Economia de baixo Carbono?; Economia Aplicada, v. 20, n. 3, pp. 273-310; https://doi.org/10.11606/1413-8050/ea146090.

Mundo Latas. [acesso em 22 mai. 2021]. Disponível em: https://mundolatas.com/pt-br/historia-da-embalagemmetalica-1a-parte-origem/

PASCHOAL, J.O.A. (2007). Slides do seminário Novas Tecnologias para Bioenergia; Instituto de Estudos Avançados da Universidade de São Paulo.

SILVA, E.A., Lins, V.F.C., Cotting, F. (2019). Processo de Moagem de Garrafas PET Pós-Consumo; The Journal of Engineering and Exact Scienses.

VALT, R. B. G., (2004). Análise do Ciclo de Vida De Embalagens de PET, de Alumínio e de Vidro para Refrigerantes no Brasil variando a Taxa de Reciclagem dos Materiais; Relatório de Defesa de Dissertação de Mestrado UFPR.

SANTOS, Andréia. (2021). Inovação de Processos e Sustentabilidade Organizacional. Tese Doutorado Universidade Fernando Pessoa. Porto. http://hdl.handle.net/10284/10164.

SAURABH, A., RAJESH, K., SINGH, Q. M. (2015). A literature review and perspectives in reverse logistics, Resources, Conservation and Recycling, Volume 97, Pages 76-92, ISSN 0921-3449. https://doi.org/10.1016/j.resconrec.2015.02.009.

SISLIAN, Rodrigo. (2020). Desenvolvimento de indicadores de desempenho para gerenciamento do consumo de água e energia em um sistema clean in place. (158 p.) Tese (doutorado) - Universidade Estadual de Campinas, Faculdade de Engenharia Química, Campinas, SP.

http://repositorio.unicamp.br/jspui/handle/REPOSIP/343589 
STEGANI, V.; MAGANHINI, M.; SILVA, Janeci; MARTINES, F.; ROSSI, J.; BOFFE, T.; GOLIAS, H. (2021); Questões Ambientais: A Visão dos Catadores de Materiais Recicláveis da Região Norte do Paraná; Revista EA. Volume XX, Número 75. ISSN 1678-0701.

TOLMASQUIM, M. T., GUERREIRO, A. GORINI, R. (2007). Matriz Energética Brasileira: Uma Prospectiva; Novos Estudos. CEBRAP 79, pp. 47-69.

ZULPO, M.; MORAIS, A. B.; Tedesco, C. D. (2020). Universidades e as dimensões da sustentabilidade: econômica, social e ambiental, uma revisão bibliográfica. Revista Ibero-Americana de Ciências Ambientais, v.11, n.4, p.406-415, 2020. DOI: http://doi.org/10.6008/CBPC2179-6858.2020.004.0033 